\title{
Combined use of galectin-3 and thyroid peroxidase improves the differential diagnosis of thyroid tumors
}

\author{
D. KALFERT ${ }^{1, *}$, M. LUDVIKOVA², I. KHOLOVA 3 , J. LUDVIK ${ }^{4, *}$, O. TOPOLCAN 5 , J. PLZAK ${ }^{1}$
}

${ }^{1}$ Department of Otorhinolaryngology and Head and Neck Surgery, University Hospital Motol, First Faculty of Medicine, Charles University, Czech Republic; ${ }^{2}$ Institute of Biology, Faculty of Medicine in Pilsen, Charles University, Pilsen, Czech Republic; ${ }^{3}$ Department of Pathology, Fimlab Laboratories and Tampere University, Faculty of Medicine and Health Technology, Tampere, Finland; ${ }^{4}$ Department of Imaging Methods, University Hospital Pilsen, Faculty of Medicine in Pilsen, Charles University, Prague, Czech Republic; ${ }^{5}$ Department of Immunochemistry, University Hospital Pilsen, Faculty of Medicine in Pilsen, Charles University, Plzen, Czech Republic

${ }^{*}$ Correspondence: ludvikj@fnplzen.cz; david.kalfert@email.cz

Received January 28, 2019 / Accepted May 2, 2019

\begin{abstract}
The differential diagnosis of well-differentiated tumors of follicular cell origin remains the most problematic task in thyroid pathology. Specific morphologic criteria (capsular and/or vascular invasion, nuclear characteristics) are crucial in the diagnosis of these neoplasms. However, the assessment of malignant features is inconclusive in some cases. Moreover, oncocytic thyroid tumors remain controversial with a respect to their pathobiology, behavior and management. Therefore, the useful diagnostic/prognostic thyroid markers are awaited. The aim of our study was to evaluate the expression of galectin-3 and thyroid peroxidase (TPO) in benign and malignant thyroid tumors of follicular cell origin. A total of 186 archival thyroid samples including 38 non-oncocytic follicular adenomas, 53 oncocytic (Hürthle cell) adenomas, 6 non-oncocytic follicular carcinomas, 23 oncocytic (Hürthle cell) carcinomas, 43 non-oncocytic papillary carcinomas, and 23 oncocytic papillary carcinomas were analyzed for galectin-3 and TPO expression by immunohistochemistry. Both types of papillary carcinomas showed significant upregulation of galectin-3 in comparison with the other tumor types, likewise, significant differences in galectin-3 expression were discovered between non-oncocytic and oncocytic variants of studied tumors excluding follicular carcinoma. Significant lowering of TPO was revealed in oncocytic adenomas and papillary carcinomas. In conclusion, the combined use of galectin-3 and TPO markers could help to improve the differential diagnosis of thyroid tumors. Differences in the galectin-3 and TPO expression between some oncocytic and non-oncocytic tumors support their separation in the latest WHO classification of thyroid tumors.
\end{abstract}

Key words: oncocytic (Hürthle cell) thyroid tumors, non-oncocytic thyroid tumors, papillary carcinoma, follicular carcinoma, follicular adenoma, thyroid peroxidase, galectin-3

The differential diagnosis of well-differentiated tumors of follicular cell origin remains the most problematic in thyroid pathology. Specific morphologic criteria (capsular and/or vascular invasion, nuclear characteristics) are crucial for the diagnosis of these neoplasms. However, assessment of malignancy features seems to be inconclusive in some cases. Both papillary and minimally invasive follicular carcinomas can be a challenge with inter-observer diagnostic variability [1]. In addition, non-neoplastic thyroid lesions may contain papillary projections and focal nuclear clearing confusing with those in papillary carcinomas. In the current WHO classification of thyroid cancer, a group of borderline thyroid tumors was for the first time introduced. In addition, oncocytic variants of various tumors were separated as entities [2]. Therefore, various diagnostic/prognostic markers are currently studied. Furthermore, useful diagnostic markers are needed in routine thyroid fine needle aspiration cytology practice to avoid surgery in certain cases [3]. Recently, galectin-3 has been proven to be expressed in neoplastic thyrocytes, although it is completely negative in normal and non-neoplastic thyroid glands. On the other hand, thyroid peroxidase (TPO) expression is altered in various thyroid diseases, including tumors [4].

Galectins are proteins that interact with glycoconjugates to produce changes in cellular activity (cell to cell and cellextracellular matrix interactions, cell migration/invasion and angiogenesis) thus supporting carcinogenesis [5]. Galectin-3 (chimera type galectin) seems to be an important player in different human diseases, namely in cancers. Galectin deregulation (up- or down-) and site of galectin expression 
(cytoplasmic, nuclear) are associated with specific cancers [6, 7]. In some tumors, galectins have promising diagnostic and/ or prognostic role or serve as a therapeutic target [7-9].

TPO plays a key role in physiological function of the thyroid gland by catalyzing the oxidation of inorganic iodide to form the thyroid hormones, thyronine and triiodothyroxin. TPO represents an important differentiation marker of the thyroid gland. In thyroid cancer, TPO expression was lower compared to benign conditions and normal tissue. Similarly, a decrease in TPO expression observed in breast cancer has the potential association with breast cancer aggressiveness and the link between breast cancer development and thyroid dysfunction [10].

The aim of our study was to evaluate galectin-3 and TPO expression in a large collection of benign and malignant, oncocytic and non-oncocytic thyroid tumors of follicular cell origin to find useful markers in the thyroid differential diagnosis with the emphasis on oncocytic tumors.

\section{Patients and methods}

Clinicopathologic data. Thyroid neoplasms selected for the study were retrieved from surgical and consultation files of two authors (M.L., D.K.). A total of 186 tumors were classified according to the criteria proposed by WHO and divided according to the histological type and dignity into six groups: 38 non-oncocytic follicular adenomas (NA); 53 oncocytic (Hürthle cell) adenomas (OA), 6 non-oncocytic follicular carcinomas (FC); 23 oncocytic (Hürthle cell) carcinomas (OC), 43 non-oncocytic variant (classical) papillary carcinomas (PC), 23 oncocytic variant of papillary carcinomas (OPC). All follicular and oncocytic carcinomas were minimally invasive. Oncocytic variants of tumors and Hürthle cell (oncocytic) tumors were defined by the presence of at least $75 \%$ thyrocytes with deeply eosinophilic cytoplasm on hematoxylin and eosin stained sections in the entire tumor. The oncocytic character of some tumor cells was verified by immunohistochemistry with the anti-mitochondrial antibody.

Inclusion criteria incorporated morphological characteristics of tumors (well-differentiated carcinomas of the oncocytic and non-oncocytic feature, all follicular carcinomas were minimally invasive, all papillary carcinomas were of the classical variant conventional feature), availability of representative paraffin blocks for immunohistochemistry with both neoplastic and non-neoplastic thyroid and without regressive changes in tumors and accessible patient's clinical data. This work was approved by the Local Ethics Committee.

Clinicopathologic characteristics are summarized in Table 1. All patients underwent surgery due to a thyroid nodule. Preoperatively ultrasound and/or cytology examination of thyroid gland mass was performed.

Immunohistochemical methods. Paraffin-embedded samples were cut into $4 \mu \mathrm{m}$ sections. Two samples from each tumor were immunohistochemically analyzed, one of them was tumor on the interface with normal thyroid tissue. The tissue sections were deparaffinized twice with $100 \%$ xylene for $15 \mathrm{~min}$ at $37^{\circ} \mathrm{C}$ and rehydrated gradually in a $100 \%$, $95 \%$ and $80 \%$ ethanol series for $10 \mathrm{~min}$ at room temperature. All immunohistochemical analyses were performed by the manual technique using immunoperoxidase method with monoclonal primary antibodies against mitochondrial antigen (clone 113-1, Biogenex, San Rammon, CA; 1:800), galectin-3 (clone 9C4, Novocastra, Newcastle upon Tyne, UK; 1:100) and TPO (clone TPO 47, Biocytex, Marseille, France; 1:20). Immunohistochemical reactions were conducted by the streptavidin-biotin-peroxidase method using SABC (Novostain ABC, Novocastra) and LSAB (Dako, Les Ulis, France) kits. The former kit was utilized for galectin-3 and mitochondrial antigen analysis, the later one for TPO immunohistochemistry. Endogenous biotin was eliminated by biotin blocking system (Dako, France). All staining steps were carried out according to the manufacturer's instructions. The reaction was developed with 3,3-diaminobenzidine (DAB, Dako, France). The slides were counterstained with Gill hematoxylin. The negative controls were performed by omitting the primary antibodies from the protocol. The internal positive control for galectin-3 was represented by endothelial cells and macrophages, respectively, and for TPO by adjacent normal thyroid tissue.

Quantitative analysis. Evaluation of galectin-3 and TPO expression was carried out by blind semi-quantitative analysis using a light microscope Olympus BX-40 equipped with a $40 \times$ magnification objective and special eye-piece $10 \times 10 \mathrm{~mm}$ grid. The galectin- 3 and TPO positivity was evaluated in tumor cells and in surrounding non-neoplastic tissues (Figure 1). The intensity of staining was not taken into consideration. On normal thyroid tissue, TPO revealed diffuse,

Table 1. Clinicopathological characteristics of the studied groups of tumors.

\begin{tabular}{|c|c|c|c|c|c|c|c|c|c|}
\hline \multirow{2}{*}{ Type of tumor } & \multirow{2}{*}{$\mathbf{N}$} & \multicolumn{2}{|c|}{ Sex } & \multicolumn{3}{|c|}{ Age (years) } & \multirow[b]{2}{*}{ Mean } & \multirow[b]{2}{*}{ Med } & \multirow[b]{2}{*}{ Range } \\
\hline & & $\mathrm{F}$ & $\mathbf{M}$ & Mean & Med & Range & & & \\
\hline Non-oncocytic follicular adenoma (NA) & 38 & 29 & 9 & 51.2 & 51.5 & $12-76$ & 32.8 & 27.5 & $10-80$ \\
\hline Oncocytic follicular adenoma (OA) & 53 & 45 & 8 & 51.4 & 52.0 & $18-88$ & 28.8 & 25.0 & $9-70$ \\
\hline Non-oncocytic follicular carcinoma (FC) & 6 & 4 & 2 & 52.2 & 60.0 & $22-73$ & 44.2 & 40.0 & $30-70$ \\
\hline Oncocytic follicular carcinoma (OC) & 23 & 16 & 7 & 56.5 & 54.0 & $35-78$ & 40.8 & 30.0 & $10-140$ \\
\hline Non-oncocytic papillary carcinoma (PC) & 43 & 36 & 7 & 45.5 & 47.0 & $12-78$ & 23.4 & 20.0 & $12-50$ \\
\hline Oncocytic papillary carcinoma (OPC) & 23 & 19 & 4 & 60.9 & 61.0 & $27-85$ & 31.7 & 27.0 & $10-70$ \\
\hline
\end{tabular}




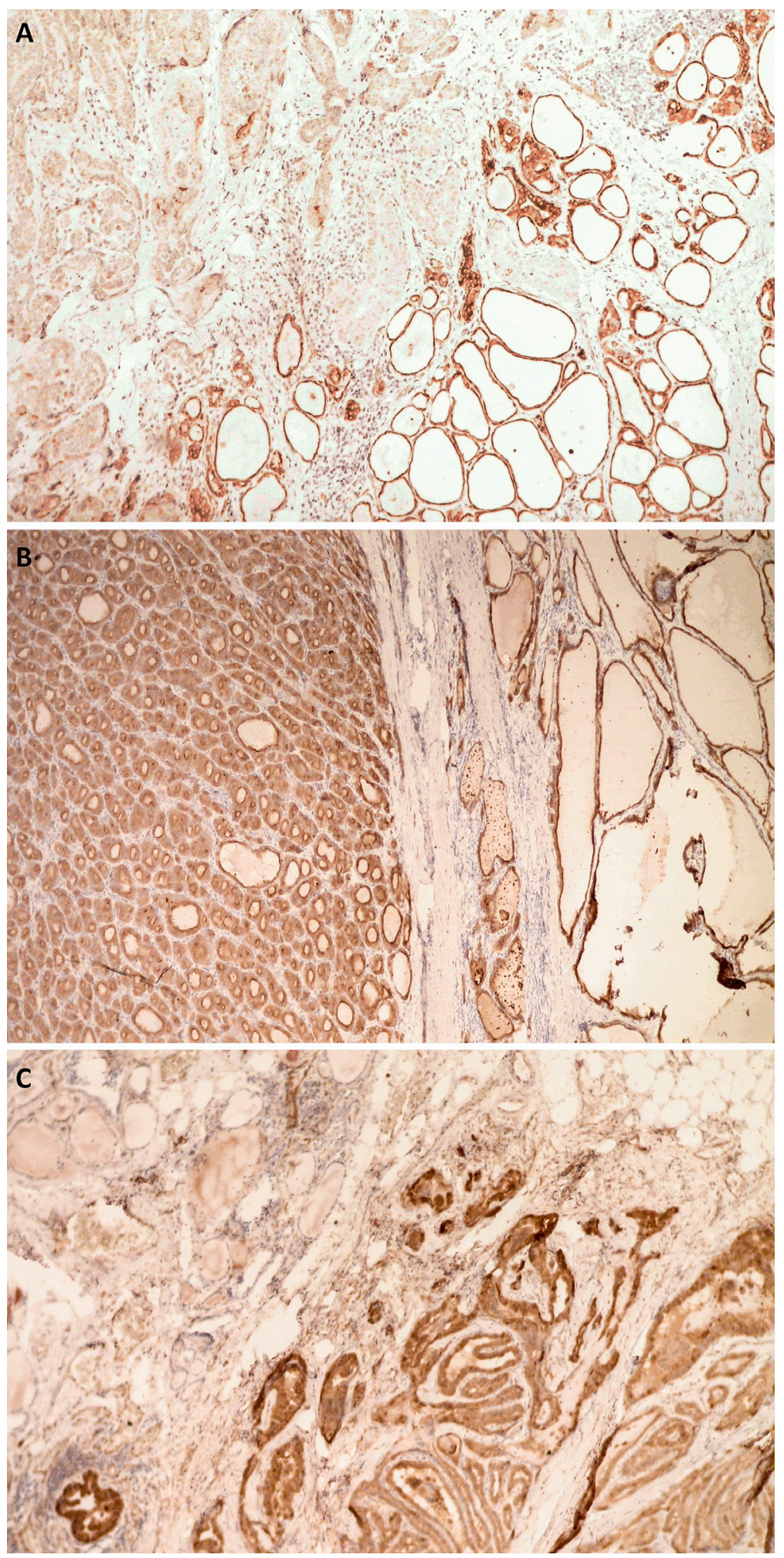

Figure 1. Immunohistochemical analyses. A) TPO is expressed in follicular cells of non-neoplastic thyroid follicles (bottom); papillary thyroid carcinoma is TPO negative (at the top) (anti-TPO; $\times 200)$. B) TPO positivity in follicular thyroid adenoma (left side) as well as in normal thyrocytes (right side) (anti-TPO; $\times 200)$. C) Papillary thyroid carcinoma showing galectin-3 positivity (right side), whereas normal thyroid follicles are galectin-3 negative (left side) (anti-galectin-3; $\times 200$ ). finely granular, cytoplasmic and membranous positivity with apical predominance. Galectin-3 was negative in non-neoplastic thyroid tissue. Galectin-3 immunoexpression was scored in tumor cells, only being detected in cytoplasm and nucleus. The percentage of the positive neoplastic cells (galectin-3 index, TPO-index) was independently evaluated by counting at least 1000 tumor cells per slide in randomly selected fields of tumors by two researchers (M.L., J.L.).

Statistical analysis. Statistical analysis was performed using the S.A.S. package, release 8.02. Mean, median, standard deviation and range were counted. The data were analyzed by the Wilcoxon test, the Fisher's exact test; $\mathrm{p}$-values equal or to less than 0.05 were considered as significant. Sensitivity and specificity, positive predictive value (PPV) and negative predictive value (NPV), and positive likelihood ratio $(\mathrm{LR}+)$ and negative likelihood ratio (LR-) were calculated with their corresponding 95\% confidence intervals.

\section{Results}

Galectin-3-immunopositive neoplastic cells showed diffuse, slightly granular, brown cytoplasmic and to lesser extent nuclear expression. Positivity of endothelial cells and macrophages served as a positive internal control. Normal and non-neoplastic (hyperplastic, inflammatory) thyroid tissue was negative. Galectin-3 indexes were assessed in all cases and were stratified to four interval sets: (1) less than $10 \%$ positive thyrocytes, (2) from $11 \%$ to $50 \%$ positive, (3) from $51 \%$ to $80 \%$ positive, and (4) more than $80 \%$ positive thyrocytes. All intervals were established in advance. Immunonegativity or low galectin-3 immunoexpression (less than $10 \%$, e.g. interval 1) prevails in adenomas (NA, OA) and follicular carcinomas (FC, OC), whereas more than $80 \%$ galectin-3 positive follicular cells were found in both variants of papillary carcinomas (PC, OPC). Comparison of galectin-3 indexes between studied groups of tumors was performed by the Wilcoxon test. All results are listed in Table 2.

In summary, galectin-3 was found in both benign, and malignant thyroid tumors of follicular cell origin, whereas it was completely negative in normal and non-neoplastic thyroid tissue. Significant differences in galectin-3 expression were found between follicular adenomas and 
papillary carcinomas (oncocytic and non-oncocytic), but not between follicular adenomas and follicular carcinomas. Interestingly, galectin-3 was significantly upregulated in papillary carcinomas in comparison with the other malignant tumors (FC, OC) $(\mathrm{p}<0.0001)$. Noteworthy, statistically significant differences in galectin-3 expression were discovered between non-oncocytic and oncocytic variants of studied tumors excluding follicular carcinoma. In addition, both oncocytic follicular adenomas and oncocytic papillary carcinomas revealed significant galectin-3 upregulation in comparison with non-oncocytic ones.

Eighty-six percent of PC and 74\% of OPC showed TPO index in the interval $1-10 \%$, and 26 cases of PC and 6 cases of OPC featured complete negativity. Oncocytic and non-oncocytic papillary carcinomas, as well as FC and OC, had TPO-index above 50\%. On the contrary, all follicular adenomas except one had TPO-index above 50\%, with most of them having more than $80 \%$. Oncocytic adenomas showed a large range in their TPO indexes from complete immunonegativity (1 case) to $100 \%$ positivity with regular distribution on the whole scale. Comparison of TPO expression between various tumor types is summarized in Table 2. Statistically significant differences were revealed between groups of benign and malignant tumors and between non-oncocytic variants of PC and FC ( $\mathrm{p}=0.0235)$, and PC revealed more decreased TPO expression than FC. Although significant differences in TPO expression were features between NA and OA (with lower TPO expression in OA), surprisingly no differences were found between oncocytic and non-oncocytic variants of both types of carcinomas.

Sensitivity, specificity, likelihood ratios (LR+ and LR-), PPV and NPV were calculated for the single and combined markers. The individual markers, TPO and Gal-3, are the most sensitive and specific for papillary carcinoma (80.95 and $75 \%$, respectively; 100 and $85.82 \%$, respectively) $(\mathrm{p}<0.001$, the Fisher's exact test). The combination of TPO and Gal-3 markers improves specificity (>94\%) for the diagnosis of papillary carcinoma $(\mathrm{p}<0.001$, the Fisher's exact test). $\mathrm{LR}+>10$ indicates that this test result has a large effect on increasing the probability of the presence of thyroid papillary carcinoma (Table 3).

\section{Discussion}

Although using the routine hematoxylin and eosin staining is the "gold standard" in diagnosis of follicular cell-derived thyroid lesions, morphologic overlap between these lesions is common to cause a diagnostic dilemma in a few cases.

Table 2. Comparison ( $\mathrm{p}$-value) of TPO and galectin-3 expression between studied groups of thyroid tumors.

\begin{tabular}{|c|c|c|c|c|c|c|c|c|}
\hline \multirow{2}{*}{\multicolumn{3}{|c|}{$\begin{array}{c}\text { Wilcoxon test } \\
\text { (p-value) }\end{array}$}} & $\mathbf{O A}$ & FC & OC & PC & OPC & Compared tumors \\
\hline & & & 0.0075 & NS & 0.0009 & $<0.0001$ & 0.0001 & NA \\
\hline \multirow{6}{*}{ TPO } & OA & $<0.0001$ & & NS & NS & $<0.0001$ & $<0.0001$ & OA \\
\hline & FC & $<0.0001$ & 0.0183 & & NS & 0.0001 & 0.0008 & GAL3 \\
\hline & OC & $<0.0001$ & $<0.0001$ & NS & & $<0.0001$ & $<0.0001$ & OC \\
\hline & PC & $<0.0001$ & $<0.0001$ & 0.0235 & 0.0018 & & 0.0149 & PC \\
\hline & OPC & $<0.0001$ & $<0.0001$ & NS & NS & NS & & \multirow{2}{*}{$\begin{array}{l}\text { Wilcoxon test } \\
\text { (p-value) }\end{array}$} \\
\hline & Compared tumors & NA & OA & FC & OC & PC & & \\
\hline
\end{tabular}

Abbreviations: TPO: thyroperoxidase; GAL3: galectin-3; OA: oncocytic adenoma; FC: non-oncocytic follicular carcinoma; OC: oncocytic follicular carcinoma; PC: non-oncocytic papillary carcinoma; OPC: oncocytic papillary carcinoma; NS: not significant.

Table 3. Sensitivities and specificities of single/combined immunomarkers galectin-3 and TPO for the diagnosis of different types of thyroid cancer (to discriminate between benign and malignant tumors).

\begin{tabular}{lllcccccc}
\hline & & & Sensitivity (\%) & Specificity (\%) & LR+ & LR- & PPV (\%) & NPV (\%) \\
\hline \multirow{4}{*}{ Gal3+/TPO- } & \multirow{2}{*}{ PC+OPC } & Value & 80.95 & 94.17 & 13.88 & 0.20 & 87.93 & 90.40 \\
& & $95 \%$ CI & $69.09-89.75$ & $88.35-97.62$ & $6.70-28.76$ & $0.12-0.34$ & $77.85-93.79$ & $84.96-94.10$ \\
& \multirow{2}{*}{ FC+OC } & Value & 10.34 & 64.29 & 0.29 & 1.39 & 5.17 & 79.20 \\
& & $95 \%$ CI & $2.19-27.35$ & $56.18-71.84$ & $0.10-0.86$ & $1.18-1.65$ & $1.80-13.09$ & $76.25-81.87$ \\
\hline \multirow{3}{*}{ Gal3+ } & \multirow{2}{*}{ PC+OPC } & Value & 100 & 85.83 & 7.06 & 0 & 78.75 & 100 \\
& & $95 \%$ CI & $94.31-100$ & $78.29-91.53$ & $4.54-10.96$ & & $70.46-85.20$ & 8.75 \\
& \multirow{2}{*}{ FC+OC } & Value & 24.14 & 52.60 & 0.51 & 1.44 & 78.64 \\
& & $95 \%$ CI & $10.30-43.54$ & $44.40-60.69$ & $0.26-0.99$ & $1.12-1.86$ & $4.69-15.73$ & $74.06-82.60$ \\
\hline \multirow{4}{*}{ TPO- } & \multirow{2}{*}{ PC+OPC } & Value & 80.95 & 75.00 & 3.24 & 0.25 & 62.96 & 88.24 \\
& & $95 \%$ CI & $69.09-89.75$ & $66.57-82.45$ & $2.33-4.51$ & $0.15-0.43$ & $54.94-70.33$ & $61.69-92.65$ \\
& \multirow{2}{*}{ FC+OC } & Value & 62.07 & 59.09 & 1.52 & 0.64 & 22.22 & 89.22 \\
& & $95 \%$ CI & $42.26-79.31$ & $50.89-66.94$ & $1.08-2.14$ & $0.40-1.04$ & $16.87-28.69$ & $83.61-93.07$ \\
\hline
\end{tabular}

Gal3+ means > 10\%; TPO- means $\leq 10 \%$; Abbreviations: LR+: positive likelihood ratio; LR-: negative likelihood ratio; PPV: positive predictive value; NPV: negative likelihood ratio; CI: confidence interval. 
Several thyroid lesions may contain papillary structures with nuclear characteristics, which may be confused with those in papillary carcinoma (for instance papillary thyroid hyperplasia, Hashimoto thyreoiditis, etc.) [11]. Moreover, papillary structures were characteristic morphological feature of PC historically, nowadays the nuclear morphology became the most overriding diagnostic consideration [12]. In most cases of conventional PC are merging with follicular pattern and solid growth pattern, notably follicular variant of papillary carcinoma with exclusively follicular pattern is also known [2]. In the present study, we focused on the single TPO and galectin-3 immunoexpression and their combined use in differential diagnosis of various types of follicular cellderived thyroid tumors, both benign and malignant, with special emphasis on oncocytic tumors.

Several tumor markers, such as cytokeratin 19 (CK19), Hector Battifora Mesothelial Epitope-1 (HBME-1), dipeptidyl peptidase IV (DPP IV), Ki-67 (MIB-1), galectin-3 and TPO were studied in thyroid tumors [8, 13-18]. Most studies focused on the expression and the diagnostic value of single marker in various thyroid lesions or in limited types of thyroid tumors [19]. However, the combination of selected markers may improve the diagnosis of thyroid tumors, especially thyroid follicular lesions. Some authors documented diagnostic results of the antibody panel of galectin-3 in the most cases in the combination with CK-19, HBME-1 and cyclin D3 [15, 18, 20-22]. Individual and combined expression of galectin- 3 and TPO and their diagnostic and prognostic potential in thyroid carcinomas was earlier evaluated only sporadically [23]. The results indicated the inverse correlation between the markers as well as the inverse correlation with selected prognostic factors [14]. Our previous studies concluded the limited use of TPO as the thyroid malignancy marker, whereas TPO in combination with DPP IV has increased its diagnostic potential $[24,25]$. In the present study, we focused on different types of thyroid tumors of follicular cell origin, both benign and malignant, with special emphasis on oncocytic tumors.

In this study, we found significant differences in galectin-3 expression between papillary carcinomas and other benign and malignant thyroid tumors on the other site. Galectin-3 expression is remarkably increased in thyroid papillary carcinomas. Galectin-3 is thus useful tumor marker for papillary carcinomas and its discrimination from papillary hyperplasia and proliferative follicular lesions. We proved no significant differences in galectin-3 expression between follicular adenomas and follicular carcinomas in our study in agreement with Mataraci et al. [26]. In contrast, Abd-El Raouf and Ibrahim found the statistically significant difference between FC and FA galectin-3 expression [27]. Galectin-3 may also help to distinguish indeterminate or suspicious FNA thyroid samples for surgical triage. Galectin-3 may, therefore, serve as a marker for diagnosis and prognosis of papillary carcinoma as was shown in the meta-analysis by Tang et al. [28].
TPO is a membrane-bound enzyme essential for the thyroid hormone synthesis. It is a marker of thyroid differentiation and normal function. It is present in the apical (colloidfaced) plasma membrane of thyrocytes. TPO gene expression is controlled by transcription factors TTF- 1 and PAX-8 [29]. TPO production is altered in various pathological conditions. Both reduction and lack of TPO expression suggests malignancy. Our results indicated significantly higher TPO expression in benign tumors in agreement with previously published data $[30,31]$. Interestingly, both types of malignant tumors featured reduction of TPO expression in our study, but papillary carcinoma revealed more decreased TPO expression than follicular carcinoma regardless of oncocytic or non-oncocytic variant. This fact probably reflects different pathobiology in both types of tumors. BRAFV660E mutation in PC was proven to be related to lower TPO expression regardless of the grade of differentiation [13].

One of our goals was to analyze galectin-3 and TPO expression in oncocytic thyroid tumors of follicular cell origin, e.g. oncocytic variant of papillary carcinomas and Hürthle (oncocytic) cell tumors in comparison to non-oncocytic tumors. To avoid misinterpretation, the influence of endogenous biotin (in oncocytic mitochondrion-rich cells) to produce false-positive results was eliminated before the immunohistochemical procedure [32]. Some authors have presented galectin-3 as a good significant marker for oncocytic follicular carcinoma [33], while the others indicated galectin-3 expression also in oncocytic adenomas [34]. In this study, significant galectin-3 overexpression was revealed in oncocytic variants of follicular adenomas and papillary carcinomas. Regarding galectin-3 expression in follicular carcinomas, differences between oncocytic and non-oncocytic variants were marginally not significant due to a low number of non-oncocytic tumors in our cohort. Significant differences were nevertheless found in TPO expression between oncocytic and non-oncocytic follicular adenomas. We are not aware of any other study comparing TPO and galectin-3 expression between oncocytic and non-oncocytic thyroid tumors of follicular cell origin. The lower TPO production in OA than in NA probably reflects a variability in their differentiation. These details of different expression of both markers between oncocytic and non-oncocytic variants of thyroid tumors supports a longtime lasting opinion that oncocytic tumors represent a pathobiologically distinct tumor subtype [35]. In agreement, oncocytic tumors are a separate entity in WHO New Classification 2017 of thyroid tumors [2].

The results of our study indicated lower sensitivity and specificity of both markers in single use for discrimination between benign and malignant thyroid lesions as well as distinct types of carcinomas. However, the combined use of them has an excellent specificity (94.1\%), relatively good sensitivity (81\%) and good likelihood ratios as test parameters for diagnosis of papillary carcinoma of oncocytic and non-oncocytic variants. Combination of galectin-3 and 
TPO was previously proven by several authors to be potential diagnostic/prognostic biomarkers for papillary carcinoma $[14,36]$.

In conclusion, to the best of our knowledge, this is the first galectin-3 and TPO study performed on comprehensive collection of benign and well-differentiated malignant thyroid tumors of follicular cell origin with an emphasis on its oncocytic and non-oncocytic variants. The combined use of galectin-3 and TPO markers could help to improve differential diagnosis of thyroid tumors, whereas the use them as a single marker remains unsatisfactory with the exception for galectin-3 expression in PC. Differences in the galectin-3 and TPO expression between oncocytic and non-oncocytic variants is another argument for a more detailed explanation of differing characteristics, behavior, and treatment of oncocytic neoplasms.

Acknowledgments: This study was supported by Ministry of Health, Czech Republic Conceptual Development of Research Organization (University Hospital in Pilsen-FNPl, 00669806) and by the Charles University Research Fund (Progres Q39 and Progres Q28/LF1(UNCE 204013). This study is a result of the research funded by the Czech Science Foundation, grant nr. 18-03978S. IK was supported by VTR grants of Pirkanmaa Hospital District and Pirkanmaa Cancer Foundation.

\section{References}

[1] FRANC B, DE LA SALMONIERE P, LANGE F, HOANG C, LOUVEL A et al. Interobserver and intraobserver reproducibility in the histopathology of follicular thyroid carcinoma. Hum Pathol 2003; 34: 1092-1100. https://doi.org/10.1016/ s0046-8177(03)00403-9

[2] LLOYD RV, OSAMURA RY, KLÖPPEL G, ROSAI J (Eds.). WHO classification of tumours of endocrine organs, 4th Edition. Stylus Publishing Inc, 2017, p 355. ISBN 978-92832-4493-6.

[3] KHOLOVA I, LUDVIKOVA M. Thyroid atypia of undetermined significance or follicular lesion of undetermined significance: an indispensable Bethesda 2010 diagnostic category or waste garbage? Acta Cytol 2014; 58: 319-329. https:// doi.org/10.1159/000366498

[4] LIU H, LIN F. Application of immunohistochemistry in thyroid pathology. Arch Pathol Lab Med 2015; 139: 67-82. https://doi.org/10.5858/arpa.2014-0056-RA

[5] KINDT N, JOURNE F, GHANEM GE, SAUSSEZ S. Galectins and Carcinogenesis: Their Role in Head and Neck Carcinomas and Thyroid Carcinomas. Int J Mol Sci 2017; 18. https://doi.org/10.3390/ijms18122745

[6] THIJSSEN VL, HEUSSCHEN R, CAERS J, GRIFFIOEN AW. Galectin expression in cancer diagnosis and prognosis: A systematic review. Biochim Biophys Acta 2015; 1855: 235-247. https://doi.org/10.1016/j.bbcan.2015.03.003[7] PLZAK J, BETKA J, SMETANA K, JR., CHOVANEC M, KALTNER $H$ et al. Galectin-3 - an emerging prognostic indicator in advanced head and neck carcinoma. EurJ Cancer 2004; 40: 2324-2330. https://doi.org/10.1016/j.ejca.2004.06.025
[8] BALAN V, NANGIA-MAKKER P, RAZ A. Galectins as cancer biomarkers. Cancers (Basel) 2010; 2: 592-610. https:// doi.org/10.3390/cancers2020592

[9] KALFEǨT D, ČELAKOVSKÝ P, LUDVÍKOVÁ M. [The significance of galectin-3 expression in glottic laryngeal squamous cell carcinoma]. Otorinolaryngol Foniatr (Prague) 2016; 65: 76-81.

[10] GODLEWSKA M, ARCZEWSKA KD, RUDZINSKA M, LYCZKOWSKA A, KRASUSKA W et al. Thyroid peroxidase (TPO) expressed in thyroid and breast tissues shows similar antigenic properties. PLoS One 2017; 12: e0179066. https:// doi.org/10.1371/journal.pone.0179066

[11] CASEY MB, LOHSE CM, LLOYD RV. Distinction between papillary thyroid hyperplasia and papillary thyroid carcinoma by immunohistochemical staining for cytokeratin 19, galectin-3, and HBME-1. Endocr Pathol 2003; 14: 55-60.

[12] LIVOLSI VA, BALOCH ZW. The many faces of follicular variant of papillary thyroid carcinoma. Pathology Case Reviews 2009; 14: 214-218. https://doi.org/10.1097/ PCR.0b013e3181c75e9b

[13] CABALLERO Y, LOPEZ-TOMASSETTI EM, FAVRE J, SANTANA JR, CABRERA JJ et al. The value of thyroperoxidase as a prognostic factor for differentiated thyroid cancer -- a long-term follow-up study. Thyroid Res 2015; 8: 12. https://doi.org/10.1186/s13044-015-0022-6

[14] SAVIN S, CVEJIC D, ISIC T, PAUNOVIC I, TATIC S et al. Thyroid peroxidase and galectin-3 immunostaining in differentiated thyroid carcinoma with clinicopathologic correlation. Hum Pathol 2008; 39: 1656-1663. https://doi. org/10.1016/j.humpath.2008.04.006

[15] LIU YY, MORREAU H, KIEVIT J, ROMIJN JA, CARRAS$\mathrm{CO} \mathrm{N}$ et al. Combined immunostaining with galectin-3, fibronectin-1, CITED-1, Hector Battifora mesothelial-1, cytokeratin-19, peroxisome proliferator-activated receptor\{gamma\}, and sodium/iodide symporter antibodies for the differential diagnosis of non-medullary thyroid carcinoma. Eur J Endocrinol 2008; 158: 375-384. https://doi. org/10.1530/EJE-07-0492

[16] GUHANANDAM H, RAJAMANI R, NOORUNNISA N, DURAIRAJ M. Expression of Cytokeratin-19 and Thyroperoxidase in Relation to Morphological Features in Non-Neoplastic and Neoplastic Lesions of Thyroid. J Clin Diagn Res 2016; 10: EC01-03. https://doi.org/10.7860/ JCDR/2016/18522.7919

[17] LUDVIKOVA M, HOLUBEC L, JR., RYSKA A, TOPOLCAN O. Proliferative markers in diagnosis of thyroid tumors: a comparative study of MIB-1 and topoisomerase II-a immunostaining. Anticancer Res 2005; 25: 1835-1840.

[18] SANUVADA R, NANDYALA R, CHOWHAN AK, BOBBIDI P, YOOTLA M et al. Value of cytokeratin-19, Hector Battifora mesothelial-1 and galectin-3 immunostaining in the diagnosis of thyroid neoplasms. J Lab Physicians 2018; 10: 200-207. https://doi.org/10.4103/JLP.JLP_106_17

[19] HUANG L, WANG X, HUANG X, GUI H, LI Y et al. Diagnostic significance of CK19, galectin-3, CD56, TPO and Ki67 expression and BRAF mutation in papillary thyroid carcinoma. Oncol Lett 2018; 15: 4269-4277. https://doi. org/10.3892/ol.2018.7873 
[20] ARCOLIA V, JOURNE F, RENAUD F, LETEURTRE E, GABIUS HJ et al. Combination of galectin-3, CK19 and HBME-1 immunostaining improves the diagnosis of thyroid cancer. Oncol Lett 2017; 14: 4183-4189. https://doi. org/10.3892/ol.2017.6719

[21] CACCHI C, ARNHOLDT HM, HAAS CJ, KRETSINGER H, AXT L et al. Galectin-3 and Cyclin D3 Immunohistochemistry and Tumor Dimensions Are Useful in Distinguishing Follicular Oncocytic Carcinomas from Oncocytic Adenomas of the Thyroid. Int J Endocrinol 2015; 2015: 276854. https://doi.org/10.1155/2015/276854

[22] DUNDEROVIC D, LIPKOVSKI JM, BORICIC I, SOLDATOVIC I, BOZIC V et al. Defining the value of CD56, CK19, Galectin 3 and HBME-1 in diagnosis of follicular cell derived lesions of thyroid with systematic review of literature. Diagn Pathol 2015; 10: 196. https://doi.org/10.1186/s13000-015-0428-4

[23] LIU Z, LI X, SHI L, MAIMAITI Y, CHEN T et al. Cytokeratin 19, thyroperoxidase, HBME-1 and galectin-3 in evaluation of aggressive behavior of papillary thyroid carcinoma. Int J Clin Exp Med 2014; 7: 2304-2308.

[24] KHOLOVÁ I, RYŠKA A, LUDVÍKOVÁ M, ČÁP J. [Thyroid peroxidase in the differential diagnosis of thyroid gland lesions. A marker of biological behavior or differentiation?]. Cesk Patol 2004; 40: 18-21.

[25] KHOLOVA I, LUDVIKOVA M, RYSKA A, TOPOLCAN O, PIKNER R et al. Diagnostic role of markers dipeptidyl peptidase IV and thyroid peroxidase in thyroid tumors. Anticancer Res 2003; 23: 871-875.

[26] MATARACI EA, OZGUVEN BY, KABUKCUOGLU F. Expression of cytokeratin 19, HBME-1 and galectin-3 in neoplastic and nonneoplastic thyroid lesions. Pol J Pathol 2012; 63: 58-64.

[27] ABD-EL RAOUF SM, IBRAHIM TR. Immunohistochemical expression of HBME-1 and galectin-3 in the differential diagnosis of follicular-derived thyroid nodules. Pathol Res Pract 2014; 210: 971-978. https://doi.org/10.1016/j. prp.2014.06.010

[28] TANG W, HUANG C, TANG C, XU J, WANG H. Galectin-3 may serve as a potential marker for diagnosis and prognosis in papillary thyroid carcinoma: a meta-analysis. Onco Targets Ther 2016; 9: 455-460. https://doi.org/10.2147/OTT.S94514
[29] DE MICCO C, KOPP F, VASSKO V, GRINO M. In situ hybridization and immunohistochemistry study of thyroid peroxidase expression in thyroid tumors. Thyroid 2000; 10: 109-115. https://doi.org/10.1089/thy.2000.10.109

[30] DE MICCO C, RUF J, CHRESTIAN MA, GROS N, HENRY JF et al. Immunohistochemical study of thyroid peroxidase in normal, hyperplastic, and neoplastic human thyroid tissues. Cancer 1991; 67: 3036-3041. https:// doi.org/10.1002/1097-0142(19910615)67:12<3036::aidcncr2820671218>3.0.co;2-d

[31] MIZUKAMI Y, HASHIMOTO T, NONOMURA A, MICHIGISHI T, NAKAMURA $S$ et al. Immunohistochemical demonstration of thyrotropin (TSH)-receptor in normal and diseased human thyroid tissues using monoclonal antibody against recombinant human TSH-receptor protein. J Clin Endocrinol Metab 1994; 79: 616-619. https://doi. org/10.1210/jcem.79.2.8045985

[32] BUSSOLATI G, GUGLIOTTA P, VOLANTE M, PACE M, PAPOTTI M. Retrieved endogenous biotin: a novel marker and a potential pitfall in diagnostic immunohistochemistry. Histopathology 1997; 31: 400-407. https://doi.org/10.1046/ j.1365-2559.1997.3020895.x

[33] VOLANTE M, BOZZALLA-CASSIONE F, DEPOMPA R, SAGGIORATO E, BARTOLAZZI A et al. Galectin-3 and HBME-1 expression in oncocytic cell tumors of the thyroid. Virchows Arch 2004; 445: 183-188. https://doi.org/10.1007/ s00428-004-1074-5

[34] MARTINS L, MATSUO SE, EBINA KN, KULCSAR MA, FRIGUGLIETTI CU et al. Galectin-3 messenger ribonucleic acid and protein are expressed in benign thyroid tumors. J Clin Endocrinol Metab 2002; 87: 4806-4810. https://doi. org/10.1210/jc.2002-020094

[35] EVANS HL, VASSILOPOULOU-SELLIN R. Follicular and Hurthle cell carcinomas of the thyroid: a comparative study. Am J Surg Pathol 1998; 22: 1512-1520. https://doi. org/10.1097/00000478-199812000-00008

[36] WEBER KB, SHROYER KR, HEINZ DE, NAWAZ S, SAID MS et al. The use of a combination of galectin-3 and thyroid peroxidase for the diagnosis and prognosis of thyroid cancer. Am J Clin Pathol 2004; 122: 524-531. https://doi. org/10.1309/UUQT-E505-PTN5-QJ7M 